Annals of Warsaw University of Life Sciences - SGGW

Land Reclamation No 47 (3), 2015: 187-201

(Ann. Warsaw Univ. of Life Sci. - SGGW, Land Reclam. 47 (3), 2015)

\title{
Experimental and numerical investigation of non-submerged flow under a sluice gate
}

\author{
ADAM KICZKO ${ }^{1}$, JANUSZ KUBRAK ${ }^{1}$, ELŻBIETA KUBRAK $^{2}$ \\ ${ }^{1}$ Department of Hydraulic Engineering, Warsaw University of Life Sciences - SGGW \\ ${ }^{2}$ Laboratory - Water Center, Warsaw University of Life Sciences - SGGW
}

\begin{abstract}
Experimental and numerical investigation of non-submerged flow under a sluice gate. The problem of sluice gate flow is analyzed using two models: a simplified one, derived according to the concept of the Potential Field (PF), and a more complex form, based on the Reynolds Average Navier-Stokes (RANS) equations. The numerical solution is compared with experimental data, including measurements performed by authors and results acquired from literature. Despite its simplicity, the PF model provides a satisfactory agreement with the measurements. The slightly worse performance of the RANS model comes from an overestimation of energy losses.
\end{abstract}

Key words: sluice gate, CFD, OpenFoam, interFoam, Potential Flow model, contraction coefficient, discharge coefficient

\section{INTRODUCTION}

A sluice gate is used in control and measurement processes in irrigation channels and hydraulic structures. The discharge under the sluice gate may be non-submerged if it is affected only by the upstream flow depth and is independent of the depth below the gate or submerged, when both the upstream and downstream flow depths are affected by the flow. Laboratory investigations of sluice gate flow are time-consuming and the results are bound to be somewhat scale-affected. Today, the computational fluid dynamics simulation of flow fields may be capa- ble of providing precise solutions to such problems (Oner et al. 2012).

The computation of flow under gates is one of the oldest classical problems in hydraulics. It comes from its practical importance and the complexity of the process. Numerous studies have been undertaken in this subject. In the engineering approach, formulas derived from the energy equation are commonly used. The simplicity is obscured by a poor representation of the process which does not allow for deeper investigations of flow properties. On the other hand, numerical solutions of sluice gate flow depend on a mathematical representation of the flow field and a discretization of a problem domain. These factors determine the practical usefulness of these methods.

Due to the development of computational techniques, especially the Finite Element Method (FEM), Finite Volume Method (FVM), a much more complex analysis of flow proprieties around the hydraulic structure becomes possible. Numerous approaches involving the FEM and FVM have been described.

Many papers have given comprehensive review of the state-of-art of models based on potential flow theory, where the real fluid is represented by a two-dimensional, irrotational, inviscid flow (Fangmeier and Strelkofff 1968, Larock 1969, 
Diersch 1976, Kubrak 1989, Montes 1997, Belaud and Litrico 2008).

Unquestionably, Computational Fluid Dynamics (CFD) represents the most sophisticated approach; however, for special problems like sluice gate flow, simplified methods might also be appropriate and effective. There are two crucial issues that distinguish specific techniques: the description of a fluid flow field and the method by which a free surface is modelled. The first case refers to the simplification level of the Navier-Stokes equations. In practical applications this might imply inter alia the formulation of Reynolds Average Navier-Stokes (RANS), Large Eddy Stimulations (LES) or an irrotational flow. The problem of a free surface evolution can be stated in the Lagrangian terms, where the free surface acts as a moving boundary and can be represented by an adaptive mesh, or in Eulerian terms, with a fixed mesh and additional equations describing the evolution of a liquid interface.

One of the first numerical experiments with the RANS model for the sluice gate problem was presented by Harlow and Welch in 1965. The authors proposed a Marker And Cell (MAC) method to model the free surface, where the location of the liquid is determined by markers moving according to the fluid flow. The development of the MAC leads to the Volume of Fluid (VoF) method, formulated by Nichols and Hirt (1975), where to each cell in the computational domain a variable referring to the amount of a fluid phase is assigned. Despite the simplicity of such an approach, due to computational costs the first CFD models of the sluice gate were mostly based on adaptive meshes.
At the beginning of the 21st century, with the rapid development of computers and CFD methods, VoF models become widely applied to various hydraulic problems, including flow through the sluice gate. The VoF modes, coupled with the finite element implementation of RANS, were used in several analyses of sluice gate flow. The most recent are by Kim (2007), Akoz et al. (2010), Cassan and Belaud (2012) and Oner et al. (2012). Except for the first, where FLOW-3D solver was used, all these applications are based on the ANSYS CFD software (ANSYS 2011).

As new CFD methods still emerge, it is useful to test their performance in solving common engineering problems. In the present study we analyze the numerical solution of sluice gate flow obtained using the VoF RANS formulae and an interFoam modeling system. It is a part of an open source framework of the OpenFoam (OpenFAOM Fundation 2012). The model performance and accuracy were tested by Deshpande et al. (2012); however, still there is a lack of applications in typical hydraulic environments, such as sluice gate flow, which is investigated in this study. Especially, the interFoam algorithm is based on a different concept of an interface (the free surface) tracking to the models used in previous studies. In FLOW-3D and ANSYS CFD solutions the free-surface is determined after evaluating the flow equations by a geometrical reconstruction of the liquid-gas interference. In the interFoam the additional term is directly implemented in the solver.

The interFoam performance is compared with a simplified model of irrotational, inviscid flow with an adaptive mesh. The numerical computations were 
verified using experimental investigations of the sluice gate flow. The experiments were conducted in the hydraulics laboratory and consist of measured inflow rate and water elevations before and after a sluice gate with a given opening. It has to be noted that the term "experiment" accounts not only for the physical measurements but also numerical simulations, also called experimental design. In the present paper both meanings are used.

\section{NON-SUBMERGED FLOW UNDER SLUICE GATE - ENGINEERING APPROACH}

The discharge through a non-submerged sluice gate flow may be expressed on the basis of the energy equation and continuity flow formula with the discharge coefficient $-C_{d}$ (Fig. 1):
$B$ - sluice gate width;

$g$ - gravitational acceleration; $H$ - water depth before the gate.

The discharge coefficient $C_{d}$ for non-submerged sluice gate flow was calculated as:

$$
C_{d}=\frac{C_{c}}{\sqrt{1+C_{c} \frac{a}{H}}}
$$

where:

$C_{c}$ - the contraction coefficient defined as the ratio of downstream water depth at the vena contracta and the gate openings as:

$$
C_{c}=h / a
$$

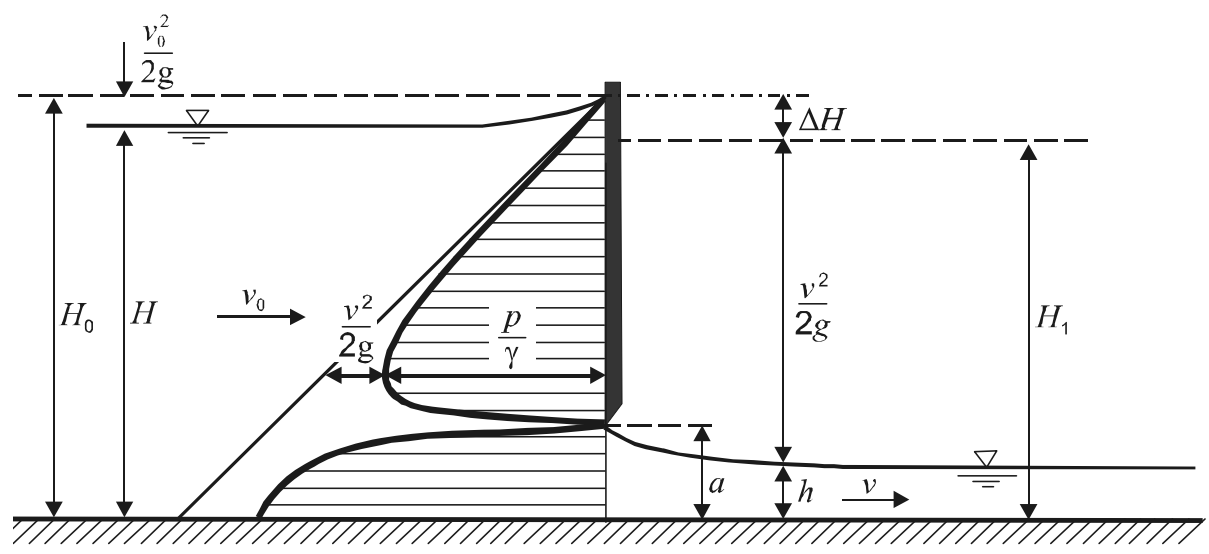

FIGURE 1. Definition plot of a sluice gate

$Q=C_{d} a B \sqrt{2 g H}$

(1)

where:

$Q$ - discharge;

$C_{d}$ - discharge coefficient;

$a$ - gate opening;

\section{EXPERIMENTAL} INVESTIGATIONS

The real flow experiments were performed in the laboratory duct, $0.31 \mathrm{~m}$ wide, $0.45 \mathrm{~m}$ high and $5 \mathrm{~m}$ long. 
Inside the device a sharp-crested gate with adjustable opening was placed. Experiments were performed for different inflow rates and constant opening heights, during which the water level before and after the gate at several locations was measured. The experimental conditions of the flow are shown in Figure 2 and given in Table 1.

\section{interFoam VoF model}

The interFoam is a RANS model of an incompressible multiphase flow. Partial differential equations are solved using the FVM discretization and the model is part of the OpenFoam library, designed mostly, but not only, for CFD problems. As the model has been developed under

TABLE 1. Measured and computed flow properties of the gate flow: $H$ - water depth before the gate, $Q$ - total discharge, $a$ - gate opening, $v_{o}$ - upstream mean velocity before contraction, $H_{o}$ - hydraulic head, $h$ - downstream water depth, $a / H_{o}$ - relative opening, $\mathrm{Re}$ - Reynolds number, $\mathrm{Fr}$ - Froude number

\begin{tabular}{|c|c|c|c|c|c|c|c|c|}
\hline $\begin{array}{c}H \\
{[\mathrm{~m}]}\end{array}$ & $\begin{array}{c}Q \\
{\left[\mathrm{~m}^{3} / \mathrm{s}\right]}\end{array}$ & $\begin{array}{c}a \\
{[\mathrm{~m}]}\end{array}$ & $\begin{array}{c}v_{o} \\
{[\mathrm{~m} / \mathrm{s}]}\end{array}$ & $\begin{array}{c}H_{o} \\
{[\mathrm{~m}]}\end{array}$ & $\begin{array}{c}h \\
{[\mathrm{~m}]}\end{array}$ & $\begin{array}{c}a / H \\
{[-]}\end{array}$ & $\begin{array}{c}\operatorname{Re} \\
{[-]}\end{array}$ & $\begin{array}{c}\mathrm{Fr} \\
{[-]}\end{array}$ \\
\hline 0.1260 & 0.0135 & 0.05 & 0.3451 & 0.1321 & 0.0315 & 0.40 & 132771 & 0.31 \\
\hline 0.1640 & 0.0159 & 0.05 & 0.3137 & 0.1685 & 0.0315 & 0.30 & 157089 & 0.25 \\
\hline 0.1940 & 0.0177 & 0.05 & 0.2935 & 0.1984 & 0.0320 & 0.26 & 173860 & 0.21 \\
\hline 0.2525 & 0.0204 & 0.05 & 0.2560 & 0.2559 & 0.0320 & 0.20 & 197374 & 0.16 \\
\hline
\end{tabular}

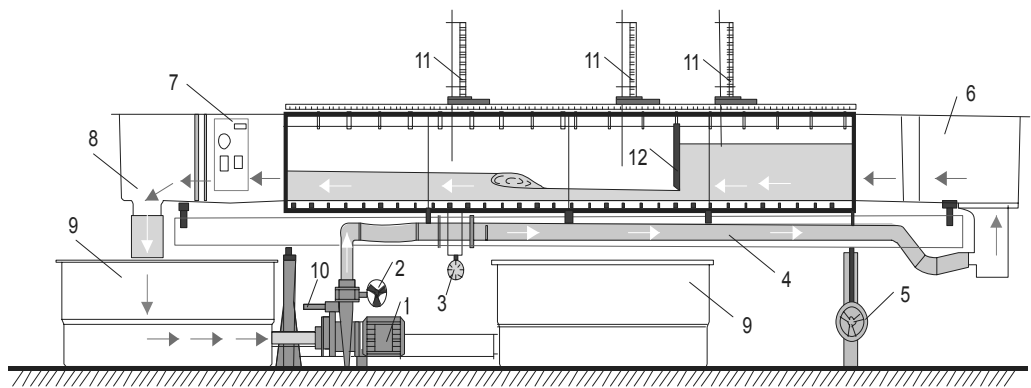

FIGURE 2. The hydraulic channel: 1 - impeller pomp, 2 - closing valve, 3 - magnetic inductive flow meter, 4 - inflow pipe, 5 - slope control, 6 - inflow section, 7 - control box, 8 - outflow, 9 - storage tank, 10 - valve, 11 - gauge, 12 - vertical sluice gate

\section{METHODS OF CALCULATION}

The methodology consists of two approaches: the RANS VoF model and the Potential Flow (PF) model with the adaptive mesh. The first presents a very general formulation of the fluid flow problem, while the second is a specific solution to sluice gate flow. the terms of the General Public License (GPL) the complete documentation is not a part of the product, but rather it is provided by the user community. Governing equations were described in detail by Deshpande et al. (2012), who focused their study on model performance issues. The short introduction of the interFoam presented in this paper is based on this article. 
The VoF approach defines a special indicator to distinguish separate flow fractions. Here, to simplify the notation, we present a two-phase: gas-liquid formulation of such an indicator $\mathrm{I}(\mathbf{x}, \mathrm{t})$, in the space $(\mathbf{x})$ and time $(\mathrm{t})$ domain $(\Omega)$ :

$$
I(\boldsymbol{x}, t)=\left\{\begin{array}{lll}
1 & \text { for } & \boldsymbol{x} \in \mathfrak{R}_{L} \\
0 & \text { for } & \boldsymbol{x} \in \mathfrak{R}_{G}
\end{array}\right.
$$

A discretization over the computational cell $\left(\Omega_{\mathrm{i}}\right)$ leads to a liquid field:

$\gamma\left(\boldsymbol{x}_{i}, t\right)=\frac{1}{\left|\Omega_{i}\right|} \int_{\Omega_{i}} I(\boldsymbol{x}, t) d V$

The value of 1 refers to a cell totally filled with liquid, 0 with gas. The continuity equation for the liquid flow takes the following form:

$\frac{\partial \gamma}{\partial t}+\nabla(\boldsymbol{U} \gamma)=0$

The crucial issue here is to preserve the discontinuous nature of an interface between gas and liquid that does not have to follow the cell boundaries. A numerical solution for $\gamma$ has to fulfil the additional constraint that would limit the interface smearing. Default methods of commonly used models (i.a. ANSYS 2011) are based on a geometrical reconstruction of interface. In the interFoam the additional constraints are directly implied, through a special limiter implemented in the MULES (Multidimensional Universal Limiter with Explicit Solution) solver.

The two-phase momentum equation takes the following form:

$$
\begin{aligned}
& \frac{\partial \rho \boldsymbol{U}}{\partial t}+\nabla \cdot(\rho \boldsymbol{U} \otimes \boldsymbol{U})= \\
& =\nabla p+[\nabla \cdot(\mu \nabla \boldsymbol{U})+\nabla \boldsymbol{U} \cdot \nabla \mu]+ \\
& +\rho g+\int_{\Gamma} \sigma \kappa \delta\left(\boldsymbol{x}-\boldsymbol{x}_{s}\right) \boldsymbol{n} d \Gamma\left(\boldsymbol{x}_{s}\right)
\end{aligned}
$$

where:

$\rho$ - density field, $\mu$ a viscosity field;

$\sigma$ - surface tension coefficient;

$\delta\left(\mathbf{x}-\mathbf{x}_{\mathrm{s}}\right)-3 \mathrm{D}$ Dirac delta function;

$\Gamma$ - gas-liquid interface;

$\kappa$ - local interfacial curvature.

The surface tension is represented by the continuum model of Brackbill et al. (1992).

The interFoam allows utilizing different turbulence models. In the present study we applied the standard k- $\varepsilon$ closure. The other model, $\mathrm{k}-\omega$ closure, would provide more precise results, as it is able to predict the turbulent length scale near the walls more accurately. However, Akoz et al. (2010), Cassan and Belaud (2012) report that the choice between these two closures is not crucial in the case of sluice gate flow.

The $\mathrm{k}-\varepsilon$ model is insensitive to adverse gradients and is unsuitable for wall regions where flow conditions are strongly affected by viscosity effects. Therefore to model the flow field near walls it is necessary to impose additional modification terms. There are two common ways to address this problem: a two-layer or wall function approach. In the first the near wall region is modelled with a modified turbulence model that includes viscous effects, whilst in the second approach the momentum fluxes are computed with a semi-empirical function, derived, e.g. from the logarithmic 
law. Beside additional equations used for turbulence modelling, the two-layer approach requires a finer mesh in the wall region than wall functions, which makes it more computationally demanding.

In modelling of sluice gate flow both approaches are utilized; Akoz et al. (2010), Oner et al (2012) use the two-layer approach, whilst Kim (2007), Cassan and Belaud (2012) apply wall functions. In our study we have applied the wall functions approach to reduce the computational cost.

The discretization of a modelled domain has a noticeable impact on the solution. Akoz et al. (2010) and Oner et al. (2012) showed how cell density can affect the free surface profile near the gate. In a case of the interFoam model we decided to apply a structured hexahedral mesh, developed with help of the blockMesh generator, provided by the OpenFoam library. As in other listed studies, it was assumed that only two flow directions are dominant and sufficient representation of the problem is given by a $2 \mathrm{D}$ formulation. Therefore, each computational cell was extended across a total channel width. For the remaining directions, height $(y)$ and length $(x)$ of the same cell size $\left(d_{x}, d_{y}\right)$ were implied. The resolution of the mesh was adjusted to buffer the wall region with single cells that accounts for a transition between a viscous sublayer and a logarithmic region, fulfilling the condition $12<y^{+}<250$, with $y^{+}=y u * v$, where $u *$ is a shear velocity. The general scheme of the mesh is given in Figure 3.

The numerical simulations were designed to reproduce the flow conditions observed during laboratory experiments. The boundary condition for a velocity at the inflow was defined in terms of a constant discharge, given by measurements. The distribution of water velocity was assumed to be uniform. The input veloc-

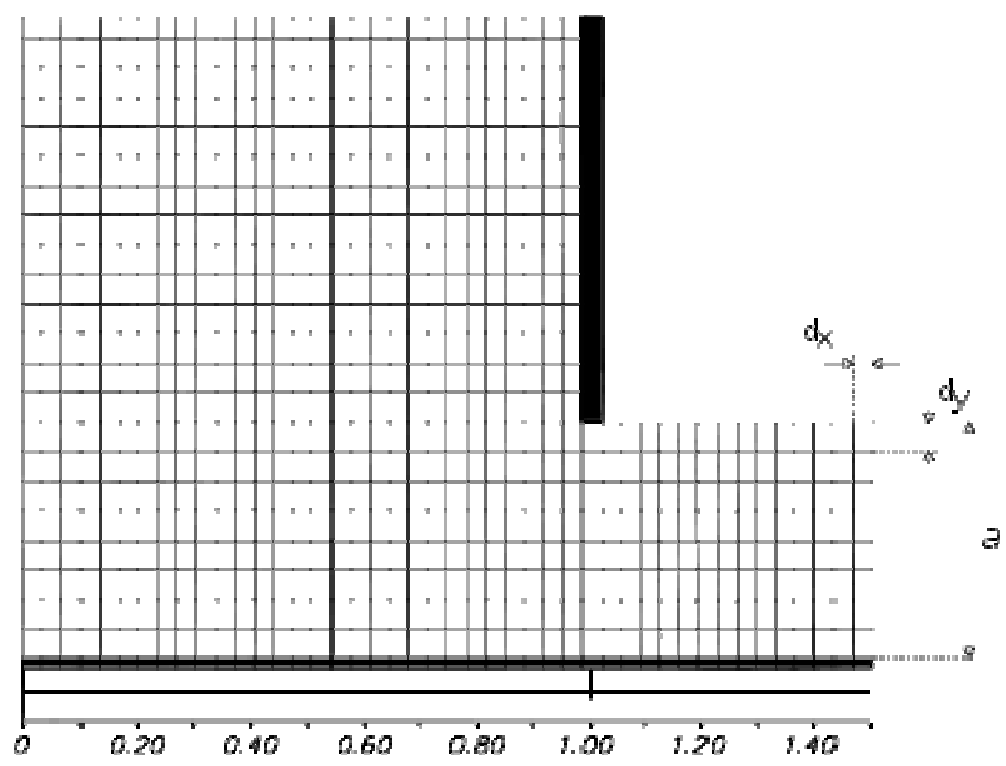

FIGURE 3. The interFoam computational mesh scheme 
ity was linked with the indicator of the phase fraction $(\gamma)$, in the following way:

$$
v_{i}=\frac{\gamma_{i} Q}{\sum_{k=1}^{N} A_{k} \gamma_{k}}
$$

where:

$v_{i}-$ velocity at a face of the $i$-th cell;

$\gamma_{i}$ - phase fraction (1 for water);

$Q$ - total inflow;

$\mathrm{N}$ - number of cells at the inlet;

$A_{i}$ - face area.

The boundary distribution of $\gamma$ at the inlet was defined to be equal to values computed at neighbour cells. In this way it was possible to obtain flexible boundary conditions that would follow a computed water level before the gate.

As mentioned above, the turbulence in wall regions (for the VoF model) was described using wall functions i.e. kqRWallFunction for turbulence insensitivity $(k)$, epsilonWallFunction for turbulence dissipation and nutkRoughWallFunction for the eddy viscosity (OpenFOAM Fundation 2012). We have adopted the default parameter values for the hydraulic smooth surfaces.

At the channel outflow, as well as for top surfaces, intended to be open to the atmosphere, boundary conditions were generally introduced in the form of a zero gradient (using InletOutlet and pressureInletOutletVelocity functions). The only exception was made for the pressure, which at the outlet face was assumed to follow the internal field. For the surfaces representing the atmosphere a fixed value was given.

To reduce the impact of the boundary conditions on the results, a reasonable distance between the boundary faces and the gate was maintained. The channel length before and after the gate amounts to 0.40 and $0.60 \mathrm{~m}$, respectively. These values were elaborated on the basis of multiple numerical tests.

For the first numerical experiment the initial conditions were defined by the constant values of all variables ant it was assumed that the whole model domain is filled by the liquid. The simulations were carried out to achieve a steady state condition. For further simulations, to speed up computations, the output from previous experiments was used as an initial condition. This reduced the time required to obtain a steady state solution.

For each measurement set, computations were performed for three mesh resolutions, given in Table 2. Results presented in this paper refer to the finest mesh, whilst medium and coarse meshes were designed for the sensitivity analysis.

TABLE 2. Computational mesh sizes for the VoF

\begin{tabular}{|l|c|c|c|}
\hline $\begin{array}{l}Q \\
{\left[\mathrm{~m}^{3} / \mathrm{s}\right]}\end{array}$ & $\begin{array}{c}\text { Finest mesh cell size } \\
\left(d_{x} \times d_{y}\right) \\
{\left[\mathrm{mm}^{2}\right]}\end{array}$ & $\begin{array}{c}\text { Medium mesh cell size } \\
\left(d_{x} \times d_{y}\right) \\
{\left[\mathrm{mm}^{2}\right]}\end{array}$ & $\begin{array}{c}\text { Coarse mesh cell size } \\
\left(d_{x} \times d_{y}\right) \\
{\left[\mathrm{mm}^{2}\right]}\end{array}$ \\
\hline 0.0135 & $1 \times 1$ & $2.5 \times 2.5$ & $5 \times 5$ \\
\hline 0.0159 & $1 \times 1 \mathrm{~mm}$ & $2.5 \times 2.5 \mathrm{~mm}$ & $5 \times 5 \mathrm{~mm}$ \\
\hline 0.0177 & $1 \times 0.5 \mathrm{~mm}$ & $1 \times 1 \mathrm{~mm}$ & $5 \times 5 \mathrm{~mm}$ \\
\hline 0.0204 & $1 \times 0.5 \mathrm{~mm}$ & $1 \times 1 \mathrm{~mm}$ & $5 \times 5 \mathrm{~mm}$ \\
\hline
\end{tabular}




\section{Potential Flow model}

The Potential Flow (PF) model is based on an equation of stationary two-dimensional and irrotational flow of a homogenous inviscid and incompressible fluid:

$\frac{\partial^{2} \Phi}{\partial^{2} x}+\frac{\partial^{2} \Phi}{\partial^{2} y}=0$

where:

$$
v_{x}=\frac{\partial \Phi}{\partial x}, v_{y}=\frac{\partial \Phi}{\partial y}
$$

denotes horizontal and vertical velocity components.

The field of the potential flow is constrained by streamlines, along which the domain is divided into elements. The streamlines downstream of the gate were elaborated to ensure that they are tangential to the velocity vector. The water surface was represented as a streamline, whose location was adjusted in an iteration process to ensure zero pressure. The downstream boundary condition was defined at the equipotential line, normal to streamlines. The algorithm used was developed by Diersch (1976) and was previously applied to the problem of sluice gate flow by Kubrak (1989).
Equation (11) was solved in an area for flow under the sluice gate bounded line $\mathrm{S}$ and points $\mathrm{ABCDEF}$ shown in Figure 4 . The boundary conditions were:

- constant velocity in the inlet cross section $\left(S_{0}\right) v_{o}=\left(\frac{\partial \Phi}{\partial n}\right)^{S_{0}}=$ const;

- constant velocity in the outlet cross section $\left(S_{1}\right) v_{1}=\left(\frac{\partial \Phi}{\partial n}\right)^{S_{1}}=$ const;

- velocity normal to an impermeable boundary is equal to zero: $S_{2}, S_{3}, S_{4}$ $\rightarrow v_{n}=0$;

- the velocity component normal to a free water surface is equal to zero;

- atmospheric pressure is equal:

$$
S_{5} \rightarrow v_{n}=0, p=p_{\text {atm }}
$$

where:

$v_{0} v_{1}, v_{2}$ - velocity normal to boundary of area;

$n$ - normal to boundary line $S$ of area $V$; $p$-pressure;

$p_{\text {atm }}-$ atmospheric pressure.

With the velocity potential function $(\Phi)$ as the primary unknown, the solution is reduced to the Laplace equation under Cauchy boundary conditions. As a result of the finite element approxima-

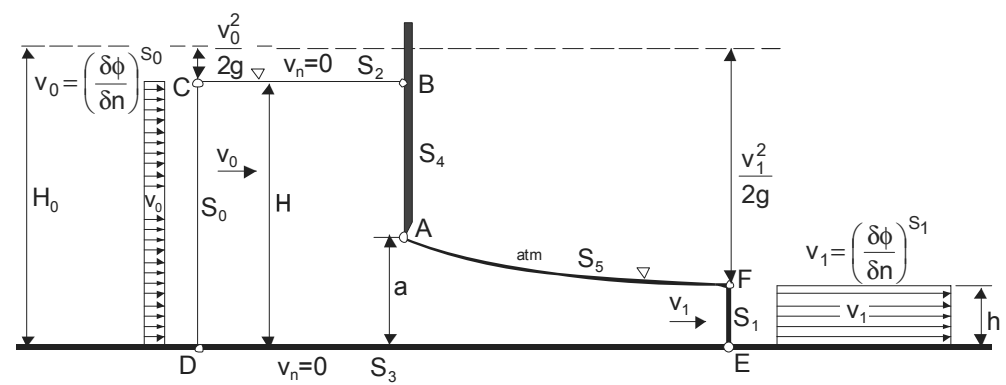

FIGURE 4. Geometry and boundary conditions of the solution domain for finite element analysis of the gate flow 
tion, a linear, symmetrical and banded system of equations is obtained that gives the nodal values of the velocity potential function as a solution. Free surface flows of fluids lead to a non-linear boundary value problem, since the surface profile is initially unknown.

For the PF model a structured irregular mesh is used. Upstream of the gate the mesh is fixed and its height corresponds to a water depth. The height of cells in a downstream part is adjusted during model iterations to ensure the zero-pressure condition at an interface. An initial shape of elements is given on the basis of an expected contraction. An example of a water profile evolution is shown along with the mesh in Figure 5.

The boundary conditions for the Potential Flow model were specified as for the interFoam (Fig. 4). The uniform velocity field was defined as $v=q / H$ at the inflow face of the mesh.
The mesh upstream of the gate was designed to model a horizontal, flat water surface at a level given by measurements (Fig. 5). For the downstream region, where the mesh is refined during the computations to identify a free surface profile, an initial element shape is assigned based on standard engineering formulas. The computations were performed for the mesh, which had 240 elements (813 nodes).

The practical solutions of flows under vertical sluice gates are determined in the following steps (details - see e.g. Kubrak 1989):

1. An assumption of a horizontal free-surface location far upstream $H$ and an initial free surface location far downstream $h$ for a given gate opening $a$.

2. Calculation of the contraction coefficient (3), discharge coefficient

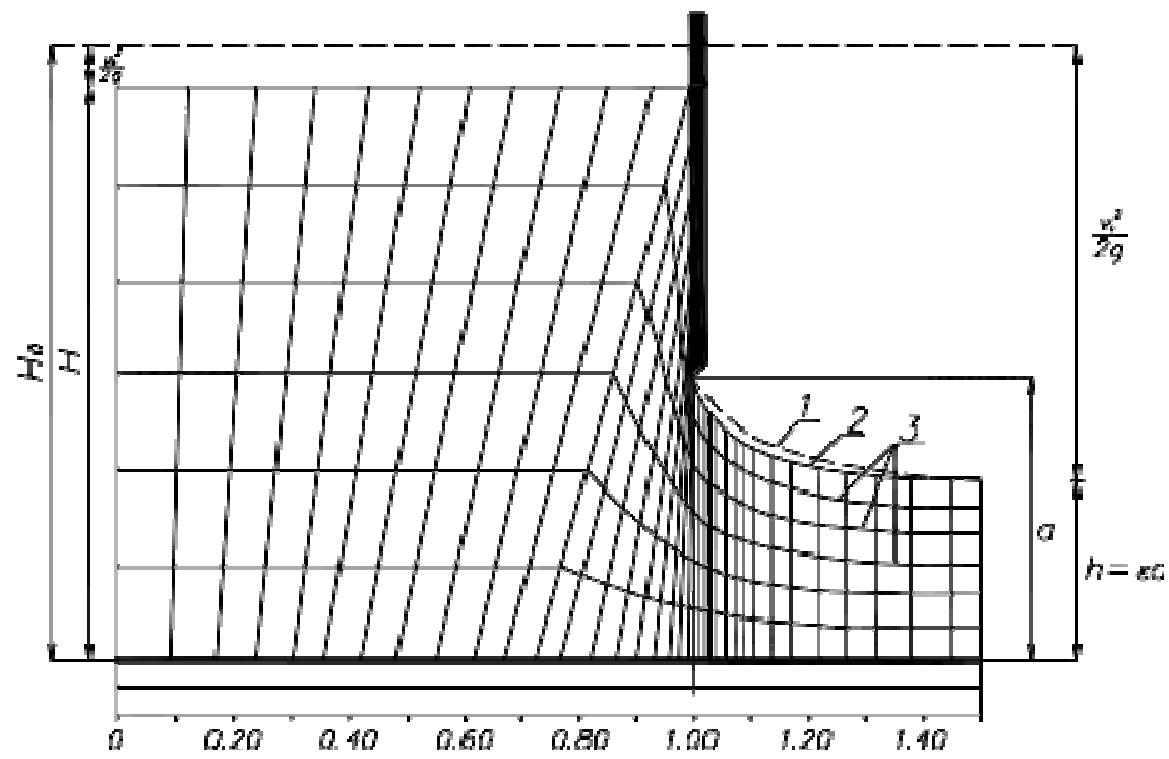

FIGURE 5. The mesh scheme of the Potential Flow model: 1, 2 and 3 refer to the streamlines shape evaluated at iterations $1-3$ 
(2), discharge (1) and the total head $H_{o}\left(H_{o}=\frac{v_{o}^{2}}{2 g}+H\right)$.

3. Finite element discretization by quadrilateral isoparametric elements of the basic flow-field (Fig. 5).

4. Calculation of the $\Phi$ values for nodes along the free surface.

5. Solution of the banded system equations, calculation of velocity components and correction of the free surface streamlines $S_{5}$.

6. Numerical control of the boundarypotential surface $S_{1}$.

7. Computation of the new total head $H_{o}$.
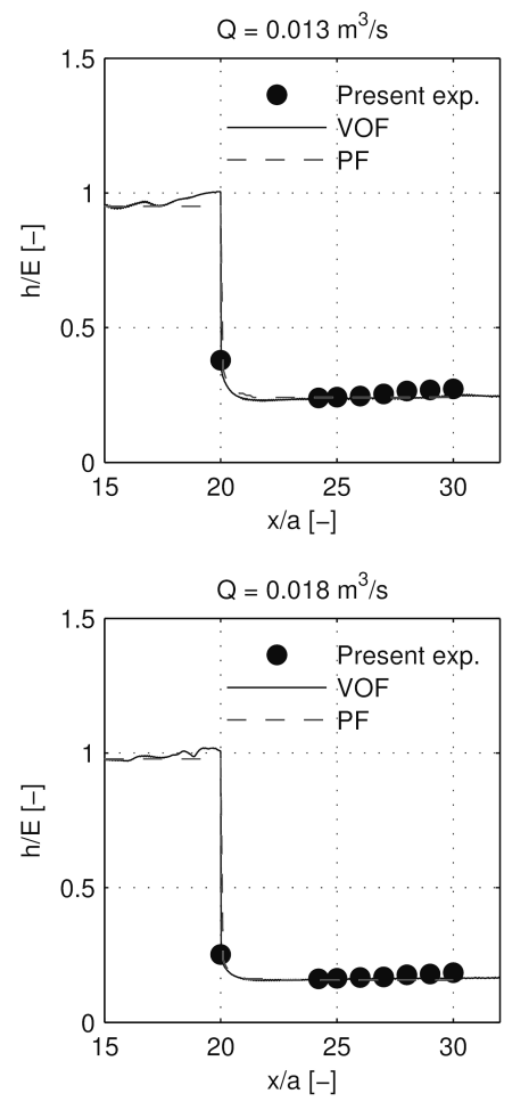

8. Repeating the computation of the free surface streamlines to satisfy the condition $\left|y_{i}^{j}-y_{i}^{j+1}\right| \leq 0.0001 m$ $\left(y_{i}^{j}, y_{i}^{j+1}\right.$ the height of nodes at the water interface in iterations).

\section{RESULTS}

The measured and calculated water profiles near the gate are illustrated by depth plots (Fig. 6). The downstream levels found using the PF model are underestimated, because of a lack of energy loss terms. For higher flows (0.018 and
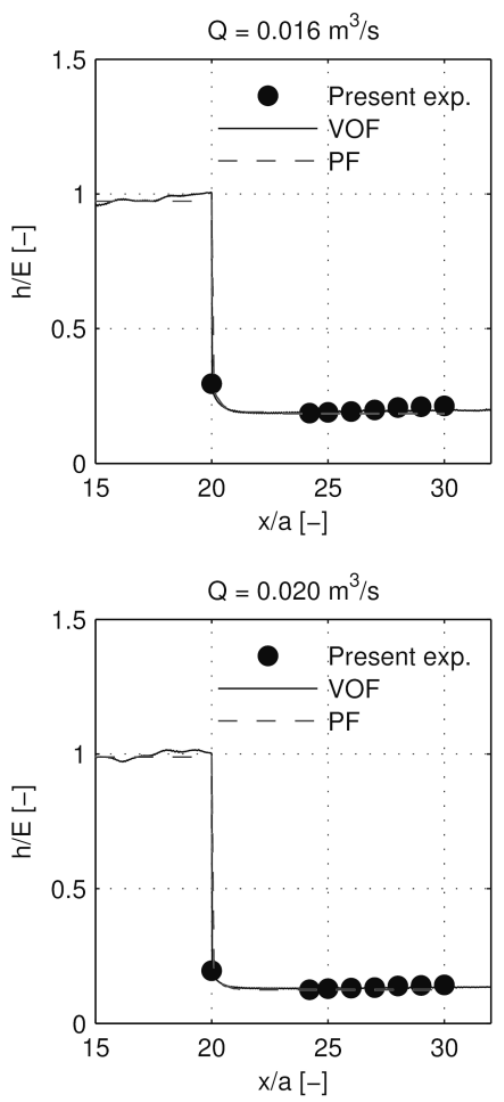

FIGURE 6. Water depths upstream and downstream of the gate 
$0.020 \mathrm{~m}^{3} / \mathrm{s}$ ) the VoF results closely follow the experimental data. For two remaining smaller discharges, the $\mathrm{VoF}$ model also underestimates downstream levels.

Apart from the standard properties of sluice gate flow the $\mathrm{VoF}$ provides a detailed description of the flow field. In Figure 7 the streamlines are shown within the distribution of the phase coefficient. It can be noticed that contraction starts approximately at a distance of 16 gate opening lengths $(x / a)$, which suggests that the velocity profile near the gate is not affected by the upper boundary condition.

The contraction coefficient $\left(C_{c}\right)$ computed by both methods and laboratory measurements can be found in Figure 8 . The differences in contraction and also $a / H$ index for $\mathrm{VoF}$ simulations comes from a small overestimation of the water levels upstream of the gate, which affects the overall hydraulic head. The overestimation of a contraction by the VoF model results from higher energy losses at the gate flow than those reported by laboratory measurements - respectively
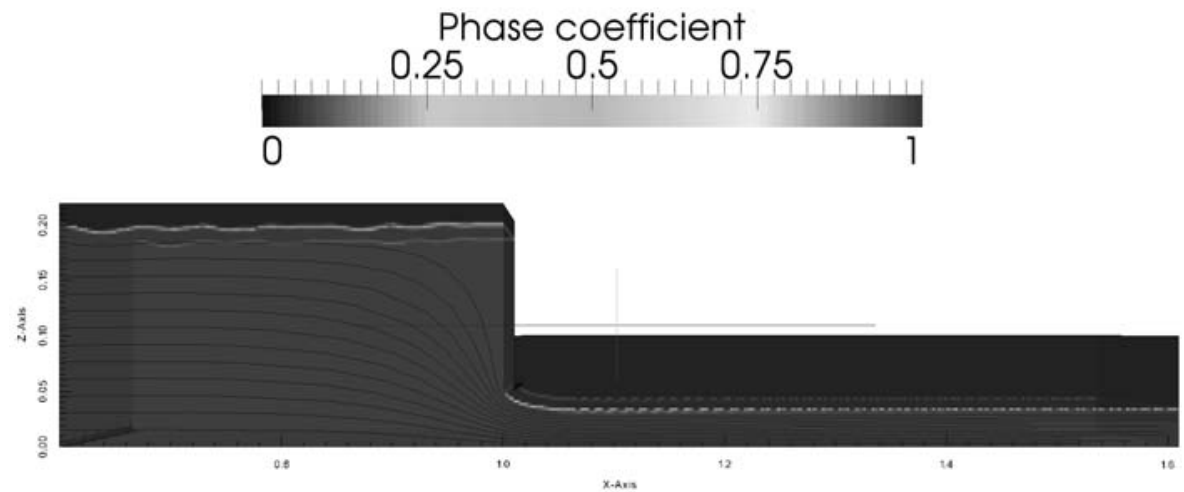

FIGURE 7. The streamlines and the phase coefficient distribution for the VoF model, for $Q=0.018 \mathrm{~m}^{3} / \mathrm{s}$

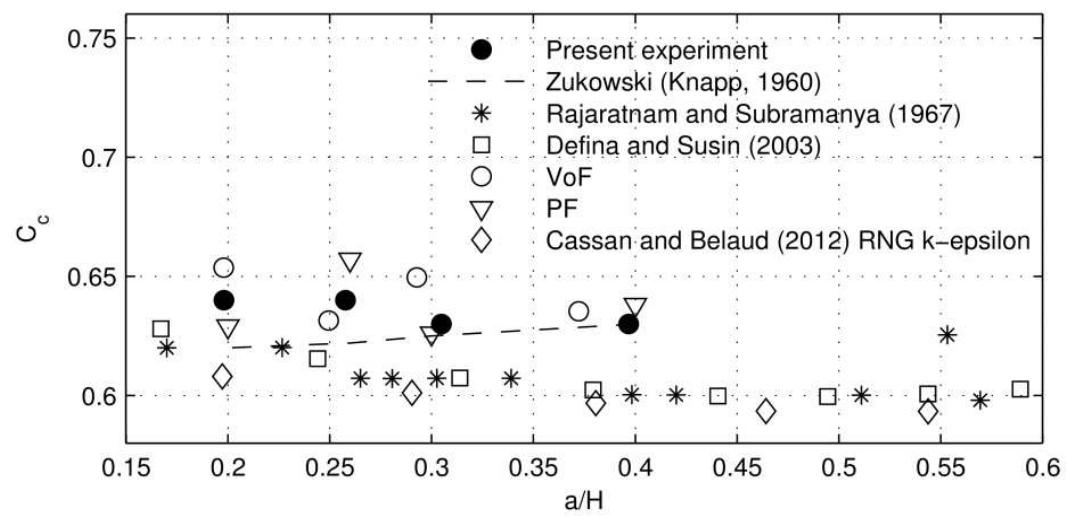

FIGURE 8. Coefficient of contraction for non-submerged sluice gate flow as a function of relative opening $a / H$ 
$10-16 \%$ to $4-2 \%$ (Fig. 8). On the other hand, even higher values of contraction were reported for the VoF model by Akoz et al. (2010) and Oner et al. (2012). The Potential Flow model gives values closer to those found in the literature.

The values were given along with experimental results of Żukowski (Knapp 1960), Rajaratnam and Subramanya (1967), Defina and Susin (2003). Values of Cassan and Belaud (2012) were obtained using the similar VoF model, with a k- $\varepsilon$ Re-Normalization Group (RNG) closure.

In Figure 9 the discharge coefficients evaluated for the present experimental data and values commonly used in practical engineering assignments (Knapp 1960) are shown together. The discharge coefficients computed from the PF solutions are closer to reference sets than those from the VoF.

\section{Sensitivity analysis}

In our study we performed a sensitivity analysis of the mesh taking advantage of the Richardson extrapolation. This methodology is in wide use in CFD applica- tions and was exploited in the sluice gate problem e.g. by Oner et al (2012). The grid quality is assessed on the basis of a grid convergence index which represents the approximated uncertainty related to the grid resolution. It is defined as (Celik et al. 2008):

$$
G C I_{\text {fine }}^{21}=\frac{1.25 e_{a}^{21}}{r_{21}^{P}-1}
$$

where:

$e_{a}^{21}$ - approximated relative error;

$r_{21}=d_{2} / d_{1}-$ grid refinement factor between grid 2 and 1 ;

$p$ - extrapolation order.

The grid indices are chosen in such way that: $d_{1}<d_{2}<d_{3}$. The $p$ order of the method is calculated iterating the following expressions:

$$
\begin{gathered}
p=\frac{1}{\ln \left(r_{21}\right)}|\ln | \varepsilon_{32} / \varepsilon_{21}|+q(p)| \\
q(p)=\ln \left(\frac{r_{21}^{p}-s}{r_{32}^{p}-s}\right) \\
s=1 \operatorname{sign}\left(\varepsilon_{32} / \varepsilon_{21}\right)
\end{gathered}
$$

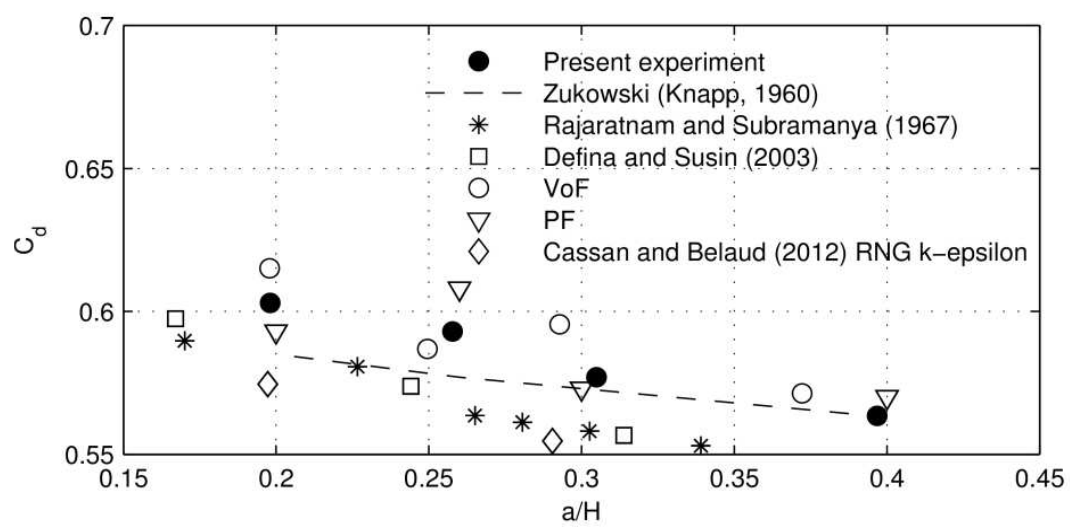

FIGURE 9. Discharge coefficient for non-submerged sluice gate flow as a function of relative opening $a / H$ 
where:

$\varepsilon_{21}=Y_{2}-Y_{1}, \varepsilon_{32}=Y_{3}-Y_{2}, Y-$ tested model output (i.e. the contraction coefficient).

Oner et al. (2012) analyzed the mesh sensitivity against the velocity at the chosen location, taking it as a model output. In our study, we apply the GCI to the contraction coefficient which provides an overall characterization of the sluice gate flow process.

For the VoF approach, the outcome value for the sensitivity analysis, the contraction coefficient (3) was computed for the minimum water level $h$ after the gate. The error estimated for the contraction coefficient computed with the finest mesh is about $3-4 \%$ with the local order of accuracy p ranging from 0.29 to 2.02 .

For the PF model the computations were performed for three mesh sizes. Here, however, cell sizes representing water depths, are a part of the solutions and it is more convenient to consider refinement in the sense of a number of nodes. The finest mesh had 240 nodes, the moderate 222 and the coarse 210 . Furthermore, the refinement was applied only to a downstream region, where velocity gradients are the highest. The sensitivity analysis revealed that the PF solution is insensitive to the mesh resolution.

\section{CONCLUSIONS}

Both models allowed simulations of sluice gate flows that were in agreement with laboratory measurements. Apparently, the PF model allowed us to obtain more accurate values than the sophisticated VoF formulation. This is caused by an overestimation of losses in the second approach, which might arise from the limitations of the k- $\varepsilon$ turbulence model, being inaccurate for flows with a strong adverse pressure gradient.

In the PF approach there is an absence of the loss term and as a result, a higher value of a contraction is determined. The same applies to water profile downstream of the gate. The assumption of a loss-less flow in the PF approach makes it impossible to reproduce an increase of water depth in the direction of the flow.

It seems that for such specific problems, simpler methods, such as the PF model, are appealing, as data and computational costs are much lower than in the case of complex methods. In particular, the results for the basic properties of the process might be at least satisfactory. The VoF model provides a solution to a wider number of applications and as an outcome adetailed description of a flow field can be obtained. However, a proper reproduction of the basic characteristics, such as the contraction coefficient, might be still an issue.

The contractions and discharge coefficients calculated from measurements are smaller than those computed based on potential flow theory; however the general agreement is satisfactory.

\section{Acknowledgments}

We are very grateful to anonymous reviewers, whose hard work allowed us to improve the article.

\section{REFERENCES}

ANSYS 2011: ANSYS FLUENT Theory Guide. Software Manual, Release 14.0. 
Akoz M.S., Kirkgoz M.S., Oner A.A. 2010: Experimental and numerical modeling of a sluice gate flow. Journal of Hydraulic Research 47(2), 167-176.

Brackbill J.U., Kothe D.B., Zemach C. 1992: A continuum method for modeling surface tension. Journal of Computational Physics 100(2), 335-354.

Belaud G., Litrico X. 2008: Closed-form solution of the potential flow in a contracted flume. Journal of Fluid Mechanics 599, 299-307.

Cassan L., Belaud G. 2012: Experimental and numerical investigation of flow under sluice gates. Journal of Hydraulic Engineering 138(4), 367-373.

Celik I.B., Ghia U., Roache P.J. 2008: Procedure for estimation and reporting of uncertainty due to discretization in CFD applications. Journal of Fluids Engineering - Transactions of the ASME, 130(7).

Defina A., Susin F.M. 2003: Hysteretic behavior of the flow under a vertical sluice gate. Physics of Fluids (1994-present), 15(9), 2541-2548.

Deshpande S.S., Anumolu L., Trujillo M.F. 2012: Evaluating the performance of the two-phase flow solver interFoam. Computational Science \& Discovery 5(1), 014016.

Diersch H.J. 1976: Finite-Element-Analysis zweidimensionaler und rotationssymmetrischer Potentialströmmungen mit freier und ohne frei Oberfläche. $\mathrm{PhD}$ thesis, Technical University Dsesden. MS.

Fangmeier D., Strelkoff T. 1968: Solution for gravity flow under a sluice gate. J. Engrg. Mech. Div. 94(EM1), 153-176.

Harlow F.H., Welch J.E. 1965: Numerical Calculation of Time-Dependent Viscous Incompressible Flow of Fluid with Free Surface. Physics of Fluids 8, 2182.

Kim D.G. 2007: Numerical analysis of free flow past a sluice gate. KSCE Journal of Civil Engineering 11, 127-132.

Knapp F.H. 1960: Ausfluss, Überfall und Durchfluss im Wasserbau. Verlag G. Braun, Karlsruhe.
Kubrak J. 1989: The results of computation of the flow under vertical sluice gates. Archiwum Hydrotechniki 36 (1-2).

Larock B. 1969: Gravity-affected flow sluice gate. J. Hydr. Div. 95(HY4), 153-176.

Montes J.S. 1997: Irrotational flow and real fluid effects under planar sluice gates. Journal of Hydraulic Engineering 123(3), 219-232.

Nichols B.D., Hirt C.W. 1975: Methods for calculating multidimensional, transient free surface flows past bodies. Proc. 1st Intl. Conf. Ship Hydrodynamics, Gaithersburg MD, 253-277.

Oner A.A., Akoz M.S., Kirkgoz M.S., Gumus V. 2012: Experimental Validation of Volume of Fluid Method for a Sluice Gate Flow. Advances in Mechanical Engineering.

OpenFOAM Fundation 2012: OpenFOAM The Open Source CFD Toolbox. Programmer's Guide. Version 2.1.1.

Rajaratnam N., Subramanya K. 1967: Flow equation for the sluice gate. Journal of Irrigation and Drainage Engineering 93(9), 167-186.

Streszczenie: Doświadczalna i numeryczna analiza niezatopionego wyplywu spod zasuwy. Niezatopiony wypływ wody spod zasuwy opisano dwoma modelami: uproszczonym, wyprowadzonym na podstawie teorii płaskiego przepływu potencjalnego (PF), i modelem o większym stopniu złożoności, bazującym na uśrednieniu Reynoldsa równań Naviera-Stokesa (RANS). Wyniki obliczeń przepustowości scharakteryzowano współczynnikami wydatku i porównano $\mathrm{z}$ wynikami własnych pomiarów hydraulicznych oraz podawanymi w literaturze. Współczynniki wydatku uzyskane z modelu PF są zbliżone do wyników badań eksperymentalnych. Nieco większe różnice wartości współczynników wydatku uzyskano z obliczeń modelem RANS. Wynika to z przeszacowania strat energii strumienia wody.

Stowa kluczowe: niezatopiony wypływ wody spod zasuwy, numeryczna mechanika płynów, OpenFoam, interFoam, przepływy potencjalne, współczynnik kontrakcji, współczynnik wydatku 


\author{
Authors' address: \\ Adam Kiczko, Janusz Kubrak, Elżbieta Kubrak \\ Katedra Inżynierii Wodnej \\ Wydział Budownictwa i Inżynierii Środowiska \\ SGGW \\ ul. Nowoursynowska 166, 02-787 Warszawa \\ Poland \\ e-mail: adam_kiczko@sggw.pl
}

